\title{
Composição mineral de alface hidropônica irrigadas com o concentrado da dessalinização de águas salobras
}

O uso de águas subterrâneas é uma alternativa para suprir a escassez hídrica em regiões semiáridas. Águas salobras são usualmente encontradas na exploração de águas subterrâneas no Nordeste do Brasil. A dessalinização via osmose inversa torna-se indispensável para o tratamento de água salobras. Com a dessalinização há a formação de água potável e do concentrado que possui níveis elevados de sais dissolvidos e pode causar impactos ambientais se descartado de forma inadequada. $\mathrm{O}$ uso do concentrado pode ser uma alternativa para o cultivo de alface em sistema hidropônico pela técnica de fluxo laminar de nutrientes. $\mathrm{O}$ objetivo do trabalho é analisar a concentração mineral nas folhas de alface cultivadas com o concentrado da dessalinização via osmose inversa. As variedades estudadas foram a crespa 'crocante' e americana 'gloriosa'. Avaliaram-se cinco níveis de condutividade elétrica a partir da diluição do concentrado (0,1; 1,1; 2,1; 3,1 e 4,1 mS $\mathrm{cm}$ 1) com delineamento inteiramente ao acaso com três repetições. O manejo dos níveis dos tratamentos consistiu em preparar a solução nutritiva e na reposição do consumo hídrico. Em geral, a concentração de potássio, sódio, cloreto, cálcio, ferro e magnésio, aumentaram com o incremento unitário de condutividade elétrica para as duas variedades estudadas e podem indicar a possibilidade do uso de água salobra nos níveis estudados para produção de alface hidropônica em regiões de acesso restrito de água doce.

Palavras-chave: Osmose inversa; Hidroponia; Nutrientes.

\section{Mineral composition of hydroponic lettuce irrigated by concentrate of dessalinization of brackish water}

\begin{abstract}
The use of groundwater is an alternative to address water scarcity in semiarid regions. Brackish waters are usually found in groundwater exploration in Northeast Brazil. Desalination via reverse osmosis becomes indispensable for the treatment of brackish water. With desalination, there is the formation of drinking water and the concentrate that has high levels of dissolved salts and can cause environmental impacts if discarded in an inadequate way. The use of the concentrate can be an alternative for the lettuce cultivation in hydroponic system by nutrient film technique. The objective of this work is analyze the mineral concentration in lettuce leaves cultivated with desalination concentrate via reverse osmosis. The varieties studied were crispy 'crocante' and american 'gloriosa'. Five levels of electrical conductivity were evaluated from the dilution of concentrate $(0.1,1.1,2.1,3.1$ and $4.1 \mathrm{mS} \mathrm{cm}-1)$ with a completely randomized design with three replicates. The management of treatment levels consisted in preparing the nutrient solution and in the restoration of water consumption. In general, the concentration of potassium, sodium, chloride, calcium, iron and magnesium increased with the unit increase of electrical conductivity for the two varieties studied and may indicate the possibility of using brackish water at the levels studied for the production of hydroponic lettuce in restricted access to freshwater.
\end{abstract}

Keywords: Reverse osmosis; Hydroponic; Nutrients.

Topic: Engenharia de Recursos Hídricos

Reviewed anonymously in the process of blind peer

Rodrigo Vieira Alves

Universidade Federal de Campina Grande, Brasi

http://lattes.cnpq.br/8676920520144608

rodrigocgnet@gmail.com

\section{Kepler Borges França}

Universidade Federal de Campina Grande, Brasil

http://lattes.cnpq.br/3620576114544758

kepler1233@gmail.com

Sonáli Amaral de Lima

Universidade Federal de Campina Grande, Brasil

http://lattes.cnpq.br/1409249976949294

sonalial@hotmail.com

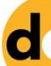

DOI: 10.6008/CBPC2179-6858.2018.002.0014
Received: 14/12/2017

Approved: 24/01/2018
Referencing this:

ALVES, R. V.; FRANÇA, K. B.; LIMA, S. A.. Composição mineral de alface hidropônica irrigadas com o concentrado da dessalinização de águas salobras. Revista Ibero Americana de Ciências Ambientais, v.9, n.2, p.160-169, 2018. DOI: http://doi.org/10.6008/CBPC2179$\underline{6858.2018 .002 .0014}$ 


\section{INTRODUÇÃO}

As regiões de clima semiárido do Nordeste brasileiro têm sofrido ao longo do tempo com problemas causados pela falta de disponibilidade hídrica, assim tecnologias inovadoras que levem aos agricultores o consórcio com a escassez de água serão sempre bem-vindas (DIAS et al., 2011). A tecnologia de dessalinização no tratamento de águas salobras subterrâneas tornou-se indispensável, assumindo uma importante alternativa de abastecimento de água nos dias atuais, tendo em vista que a composição geológica do Nordeste favorece o aparecimento de águas salobras. Até o ano de 2015, foram instalados por órgãos federais, estaduais e municipais mais de 2.000 dessalinizadores no Nordeste (CAVALCANTI, 2015; SÁNCHEZ, 2015).

Durante o processo de dessalinização há a formação do permeado (água potável) e do concentrado (água imprópria para o consumo humano) com elevada concentração de sais, podendo causar mudanças ambientais a exemplo da salinização do solo (BOYSEN et al., 2014). Os volumes de concentrado produzidos por sistemas de dessalinização podem ser reduzidos com a aplicação direta ou indireta no manejo da solução nutritiva em práticas hidropônicas sendo uma alternativa para geração de renda e alimento.

Usualmente, as diluições dos fertilizantes das soluções nutritivas hidropônicas para cultivo de alface e as reposições de evapotranspirações são feitas com água de baixa salinidade para promover melhor qualidade dos alimentos (PAULUS et al., 2012). A hidroponia difere do cultivo convencional, com vantagens para o consumidor, produtor e para o meio ambiente, como: produtos de qualidade, ciclo curto, maior produtividade, menor gasto de água, menor gasto de insumos agrícolas, mão-de-obra reduzida e produção durante todo o ano.

No Brasil, a alface (lactuca sativa) é a folhosa mais produzida em hidroponia pela NFT - Nutrient Film Technique (ALVES et al., 2011). Variedades de alfaces têm sido estudada por vários autores em hidroponia NFT, com uso de água salinizada por meio de cloreto de sódio. Soares et al. (2010) estudou a variedade 'Vera'. Paulus et al. (2012) a variedade 'verônica' e 'pira roxa', Soares et al. (2015) a variedade 'Tainá' e avaliaram parâmetros de crescimento das culturas.

Sarmento et al. (2014) avaliaram as alfaces variedades 'verônica e quatro estações' cultivadas em fibra de coco irrigada com o uso do rejeito da dessalinização na solução nutritiva para estudar a conservação refrigerada, e apresentaram boa aparência tanto na colheita como após três dias de refrigeração. Sanchez et al. (2015) afirma que na América do Sul estudos com o uso do concentrado para criação de peixes e irrigação no solo de plantas halófitas são bastante empregados com o objetivo de reduzir os volumes de concentrados produzidos pelos sistemas de dessalinização da região.

As pesquisas envolvendo alface hidropônica com diferentes substratos e tipos de águas salobras, demonstram um crescimento da necessidade de utilizar águas com qualidade inferior para irrigação, tendo em vista o uso de águas doces exclusivamente para fins de potabilidade. Desse modo, o objetivo deste trabalho é avaliar os efeitos do concentrado da dessalinização sobre os parâmetros minerais em alface hidropônica. 


\section{MATERIAIS E MÉTODOS}

Os experimentos foram realizados durante o período de janeiro a junho de 2016 em casa de vegetação no Laboratório de Referência em Dessalinização - LABDES da Universidade Federal de Campina Grande - UFCG. A casa de vegetação era composta de: alumínio com teto estilo capela com dimensões de 3,50 metros de comprimento e 1,50 m de largura totalizando $7 \mathrm{~m}^{2}$ em seu interior e 2,00 m de pé-direito. Era protegida, no teto e nas laterais, por filme agrícola de polietileno difusor de luz 125 micras presas com perfil e mola.

Foram montadas no interior da casa de vegetação 15 parcelas experimentais, de acordo com a Figura 1, compostas individualmente por: um perfil hidropônico NFT de polipropileno de $90 \mathrm{~cm}$ de comprimento, 8 $\mathrm{cm}$ de largura, 4,5 cm de altura (interior do perfil), 3 orifícios, distância entre os orifícios de $25 \mathrm{~cm}$ e diâmetro dos orifícios de $5 \mathrm{~cm}$; reservatório com capacidade para $3 \mathrm{~L}$ de solução nutritiva revestido com lona tipo blackout preto/branco $150 \mu \mathrm{m}$; sistema injetor composto por uma mangueira de $6 \mathrm{~mm}$ de diâmetro engatada a uma bomba submersa (Sarlo Better mini 220v) com vazão média de 1,8 L/min para conduzir a solução nutritiva; sistema de retorno da solução com uma mangueira $25 \mathrm{~mm}$ de diâmetro acoplada a um tubo de policloreto de vinila preso com veda calha ao perfil para o retorno da solução até o reservatório.

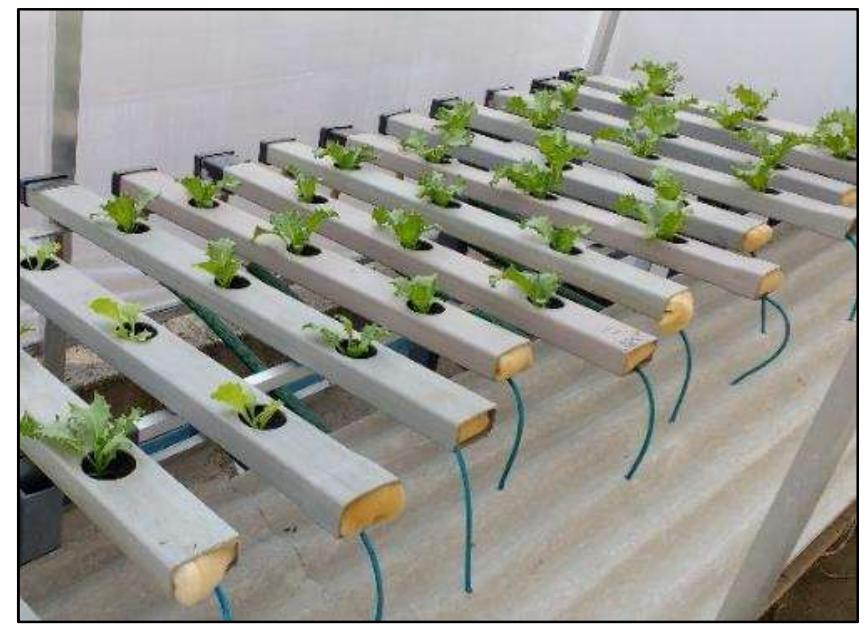

Figura 1: Interior da casa de vegetação utilizada para desenvolver os experimentos com alface hidropônica pela técnica de fluxo de nutrientes (NFT).

As parcelas experimentais foram montadas lado a lado a uma altura de 0,7 metro do solo, possuindo 4 pontos de apoio, espaçamento de 0,2 metros entre parcelas e com média de 8 horas de exposição solar. Todas as parcelas experimentais possuíam as mesmas medidas a fim de manter a homogeneidade das unidades experimentais que justificam o tipo de planejamento escolhido. $O$ concentrado da dessalinização foi obtido do sistema de dessalinização localizado no distrito Santa Luzia do município de Picuí/PB que foi implantado e monitorado pelo LABDES. Duas variedades de alface foram estudadas: no experimento I a alface crespa 'crocante' e no experimento Il a alface americana 'gloriosa'.

Avaliaram-se cinco níveis de condutividade elétrica (CEa) a partir da diluição do concentrado coletado $\left(0,1 ; 1,1 ; 2,1 ; 3,1\right.$ e 4,1 mS cm$\left.{ }^{-1}\right)$, nomeados de T1; T2; T3; T4 e T5. O nível T1 foi considerado o controle e consistiu apenas de água dessalinizada produzida no LABDES. A aplicação do concentrado utilizado neste 
trabalho consistiu em preparar a solução nutritiva e repor as perdas diárias de água por evapotranspiração a partir das diluições durante 35 dias.

Os experimentos foram conduzidos pelo delineamento inteiramente casualizado (DIC), aplicando-se cinco níveis de condutividades elétricas e três repetições. A solução nutritiva utilizada foi preparada de acordo com a solução de Furlani (1998) para cultivo de folhosas em hidroponia NFT com condutividade

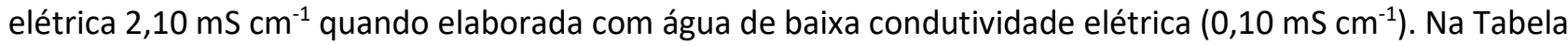
1 são apresentadas as composições para preparar 1.000 litros de solução. Os kits de nutrientes foram adquiridos em empresa de adubos especializadas em hidroponia.

No primeiro dia de cultivo, a todos os tratamentos foram acrescidos dos nutrientes e nos demais dias de cultivo foram realizadas apenas as reposições diárias com as diluições do concentrado, não havendo reposição diária de nutrientes para os níveis de tratamentos T2, T3, T4 e T5, apenas para o T1. Também não houve troca de solução nutritiva durante os experimentos.

Tabela 1: Quantidades de sais fertilizantes para o preparo de $1.000 \mathrm{~L}$ de solução nutritiva.

\begin{tabular}{ll}
\hline Fertilizante & Quantidade $\mathbf{( \mathbf { g } ^ { \mathbf { 1 0 0 0 } } \mathbf { ~ L } ^ { - 1 } \mathbf { ) }}$ \\
\hline Nitrato de Cálcio & 750 \\
Nitrato de Potássio & 500 \\
Fosfato monoamônio & 150 \\
Sulfato de Magnésio & 450 \\
Ferro (6\%) & 30 \\
Micros light (Mo, B, Zn, Cu, Mn e Ni) & 10 \\
\hline
\end{tabular}

Fonte: Furlani (1998).

Aos 35 dias, no momento da colheita, a massa fresca da parte aérea (MFPA) das plantas foram pesadas em balança analítica, utilizou-se também a razão a/b entre os coeficientes angular (a) e linear (b) para estimar as reduções percentuais na variável MFPA analisadas por incremento unitário da CEa. Em seguida as amostras foram secas em estufa a 105ㄷ e carbonizadas integralmente em cápsulas de porcelana com auxílio de bico de Bunsen, o material carbonizado foi incinerado em forno com temperatura de 550ㄷ para obtenção das cinzas e análise da composição mineral das plantas, em triplicata (IAL, 2008).

A quantificação dos minerais foi realizada via fluorescência de raios-X por energia dispersiva (SHIMADZU, EDX-720) (AOAC, 1997). As análises foram realizadas pelo laboratório de engenharia de

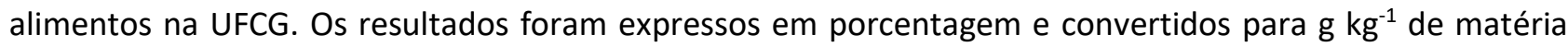
seca. A análise por fluorescência de raios-X tem finalidade quantitativa e baseia-se na medição das intensidades dos raios-X característicos emitidos pelos elementos que constituem a amostra, o método é empregado em análises da composição mineral em alimentos (SANTOS et al., 2013; GUSMÃO et al., 2015). Também foram realizadas análises físico-químicas dos cinco níveis de tratamentos segundo as metodologias descritas no (APHA, 2005). Os resultados obtidos foram submetidos ao programa IBM SPSS statistics 22 para análise de variância pelo teste $p<(0,05)$ e regressão. 


\section{RESULTADOS E DISCUSSÃO}

Na Tabela 2 estão apresentadas as características físico-químicas da água que foi utilizada para o cultivo das duas variedades de alface no sistema hidropônico. Observa-se que, com exceção do tratamento T1, as diluições do concentrado obtidas do sistema de dessalinização possuem características salobras de acordo com o CONAMA 357 de 2005 que classifica água salobra com sólidos totais dissolvidos variando entre 500 e $30.000 \mathrm{mg} \mathrm{L}^{-1}$.

Tabela 2: Análise físico química do tratamento controle e das diluições preparadas a partir do concentrado.

\begin{tabular}{|c|c|c|c|c|c|}
\hline \multirow{2}{*}{ Parâmetros } & \multicolumn{5}{|c|}{ Tratamentos } \\
\hline & T1 & T2 & T3 & T4 & T5 \\
\hline Condutividade elétrica $\mathrm{mS} \mathrm{cm}^{-1}$ & 0,10 & 1,14 & 2,10 & 3,10 & 4,14 \\
\hline $\mathrm{pH}$ & 6,1 & 7,0 & 7,1 & 7,1 & 7,3 \\
\hline Dureza total, $\mathrm{mg} \mathrm{CaCO}_{3} \mathrm{~L}^{-1}$ & 5,8 & 236,2 & 423,7 & 660,0 & 883,7 \\
\hline Cálcio, mg L-1 & 2,0 & 31,0 & 50,0 & 81,0 & 122,5 \\
\hline Magnésio, mg L-1 & 0,2 & 38,1 & 71,7 & 109,8 & 138,6 \\
\hline Sódio, $\mathrm{mg} \mathrm{L}^{-1}$ & 19,6 & 78,1 & 195,7 & 295,1 & 415,1 \\
\hline Potássio, mg L-1 & 0,2 & 3,1 & 6,37 & 10,3 & 12,7 \\
\hline Carbonatos, $\mathrm{mg} \mathrm{CaCO}_{3} \mathrm{~L}^{-1}$ & 0,0 & 0,0 & 0,0 & 0,0 & 0,0 \\
\hline Bicarbonatos, $\mathrm{mg} \mathrm{CaCO}_{3} \mathrm{~L}^{-1}$ & 6,2 & 14,0 & 30,0 & 48,0 & 110,0 \\
\hline Sulfato, $\mathrm{mg} \mathrm{L}^{-1}$ & 3,5 & 3,4 & 10,8 & 17,1 & 34,3 \\
\hline Cloreto, $\mathrm{mg} \mathrm{L}^{-1}$ & 24,9 & 353,2 & 672,7 & 995,7 & $1.249,6$ \\
\hline Amônia, mg L-1 & 0,0 & 0,9 & 2,3 & 3,9 & 5,2 \\
\hline Sólidos Totais Dissolvidos, $\mathrm{mg} \mathrm{L}^{-1}$ & 57,3 & 524,1 & $1.050,2$ & $1.567,8$ & $2.107,1$ \\
\hline
\end{tabular}

Através da análise via EDX foram identificados em maiores quantidades o potássio, sódio, cloreto, cálcio, ferro e magnésio. Outros nutrientes foram identificados apenas traços impossibilitando a quantificação como o fósforo, enxofre e zinco. Na Tabela 3 estão os resultados da ANOVA dos experimentos avaliados. $\mathrm{O}$ aumento dos níveis de CEa foi significativo $(\mathrm{p}<0,05)$ para os parâmetros de sódio e cloretos das duas variedades estudadas e do cálcio apenas no experimento II. Para os demais parâmetros, o acúmulo de minerais nas folhas não foi influenciado com o aumento da CEa dos tratamentos.

Tabela 3: ANOVA dos parâmetros minerais avaliados por tratamentos.

\begin{tabular}{|c|c|c|c|c|}
\hline Parâmetros & Experimento & SQ & QM & Valor $p$ \\
\hline \multirow{2}{*}{ Potássio } & 1 & 1334,30 & 333,57 & 0,03 \\
\hline & II & 1218,55 & 304,64 & 0,11 \\
\hline \multirow{2}{*}{ Sódio } & 1 & 572,68 & 143,17 & 0,00 \\
\hline & II & 131,21 & 32,80 & 0,00 \\
\hline \multirow{2}{*}{ Cloreto } & 1 & 4255,10 & 1063,77 & 0,00 \\
\hline & II & 2167,13 & 541,78 & 0,00 \\
\hline \multirow{2}{*}{ Cálcio } & 1 & 4255,10 & 1063,77 & 0,06 \\
\hline & II & 157,90 & 39,47 & 0,02 \\
\hline \multirow{2}{*}{ Ferro } & 1 & 4,30 & 1,07 & 0,17 \\
\hline & II & 0,76 & 0,19 & 0,72 \\
\hline \multirow{2}{*}{ Magnésio } & 1 & 4,30 & 1,07 & 0,07 \\
\hline & II & 12,98 & 3,24 & 0,14 \\
\hline \multirow{2}{*}{ MFPA } & 1 & 12821,79 & 3205,44 & 0,00 \\
\hline & II & 10620,88 & 2655,22 & 0,00 \\
\hline
\end{tabular}

SQ - Soma dos quadrados; QM - quadrado médio.

Na Figura 2A e 2B estão apresentados os resultados das concentrações de potássio e sódio para as duas variedades de alface estudadas. Em geral a concentração de potássio aumentou nos últimos níveis dos tratamentos até em média $70,0 \mathrm{~g} \mathrm{~kg}^{-1}$ para as duas variedades estudadas, esses resultados estão acima das 
concentrações recomendadas por Malavolta (2006) de $50,0 \mathrm{~g} \mathrm{~kg}^{-1}$, no entanto o autor não relaciona o excesso desse nutriente com nenhum efeito fitotóxico na planta.
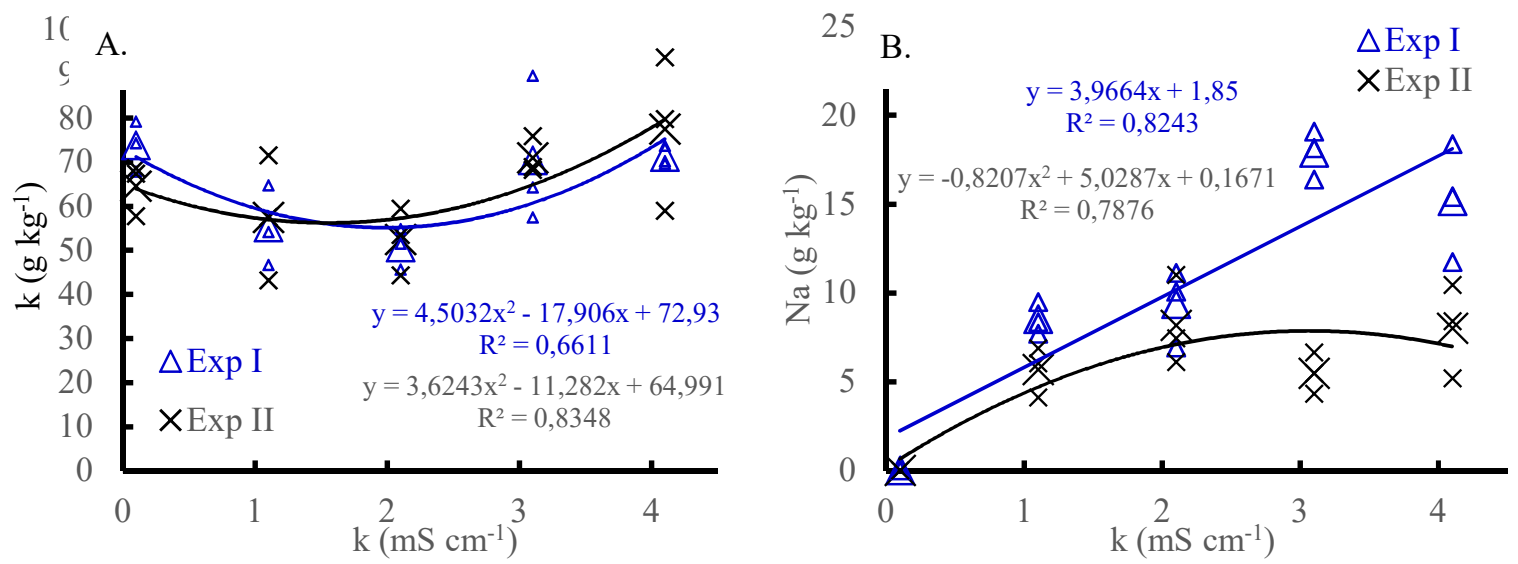

Figura 2: Concentração de potássio (A) e sódio (B) nas folhas da alface crespa e americana em função do aumento da condutividade elétrica.

Malavolta (2006), afirma que o potássio nas plantas auxilia na síntese de proteínas, nos processos osmóticos e funcionamento dos cloroplastos e fotossíntese. A deficiência de potássio pode causar clorose seguida de necrose das margens e pontas das folhas. No trabalho de Paulus et al. (2012) foi encontrado valores variando de 56,0 a $27,0 \mathrm{~g} \mathrm{~kg}^{-1}$ de potássio nas folhas de alface crespa variedade 'verônica' e houve surgimento de clorose nas folhas, provavelmente relacionado com a diminuição do potássio nas folhas.

Os resultados de potássio no presente trabalho foram superiores aos resultados de Paulus et al. (2012), devido ao tipo de água utilizada nos experimentos, que neste trabalho foi o concentrado da dessalinização que contem potássio em sua composição e ajudou a manter a concentração nas folhas de alface. Os resultados deste trabalho estão de acordo com Soares et al. (2016) avaliando a alface americana variedade 'Tainá', também encontrou resultados variando de 85,0 a $65,0 \mathrm{~g} \mathrm{~kg}^{-1}$ de potássio nos tratamentos de 0,2 a 5,2 $\mathrm{mS} \mathrm{cm}^{-1}$ respectivamente, no entanto os resultados foram decrescentes com o aumento da CEa, salientando que esses autores usaram água salinizada com $\mathrm{NaCl}$, não havendo potássio na água de reposição da solução nutritiva.

As concentrações foliares de sódio não foram identificadas nos tratamentos controle em todos os experimentos, isso porque no tratamento controle havia apenas os sais fertilizantes diluídos em água dessalinizada com CEa de $0,1 \mathrm{mS} \mathrm{cm}^{-1}$. No entanto para os demais tratamentos, com o aumento da CEa, os níveis de sódio aumentaram até a concentração máxima de 15,3 e $8,4 \mathrm{~g} \mathrm{~kg}^{-1}$ no tratamento T5 dos experimentos I e II, esse aumento foi mais acentuado no experimento com alface crespa.

Paulus et al. (2012) e Soares et al. (2016), ofertaram o estresse salino às plantas durante 21 dias e direcionaram a baixa produtividade aos níveis de CEa que foram preparados a partir da adição de 4,095 g. $\mathrm{L}^{-1}$ de $\mathrm{NaCl}$, aproximadamente $1.600 \mathrm{mg} \mathrm{L}^{-1}$ de $\mathrm{Na}^{+}$nos experimentos mais salobros e encontraram concentrações de sódio de 38,0 e $35,0 \mathrm{~g} \mathrm{~kg}^{-1}$ nos tratamentos mais salobros. No presente trabalho, a quantidade de sódio na solução nutritiva do tratamento mais salobro foi de $415,1 \mathrm{mg} \mathrm{L}^{-1}$, por esse motivo 
foram observadas concentrações menores acumuladas nas folhas das planas, observa-se também que a alface crespa acumulou mais sódio do que a alface americana.

Verifica-se na Figuras 3A e 3B as regressões das concentrações de cloretos e cálcio encontradas nos experimentos ao cultivar alface crespa e americana com os níveis de condutividades elétricas estudados. Também não foram identificados cloretos nos tratamentos controle e aumentaram até o nível mais salobro em média para 44,6 e 31,5 $\mathrm{g} \mathrm{kg}^{-1}$ nos experimentos I e II respectivamente.
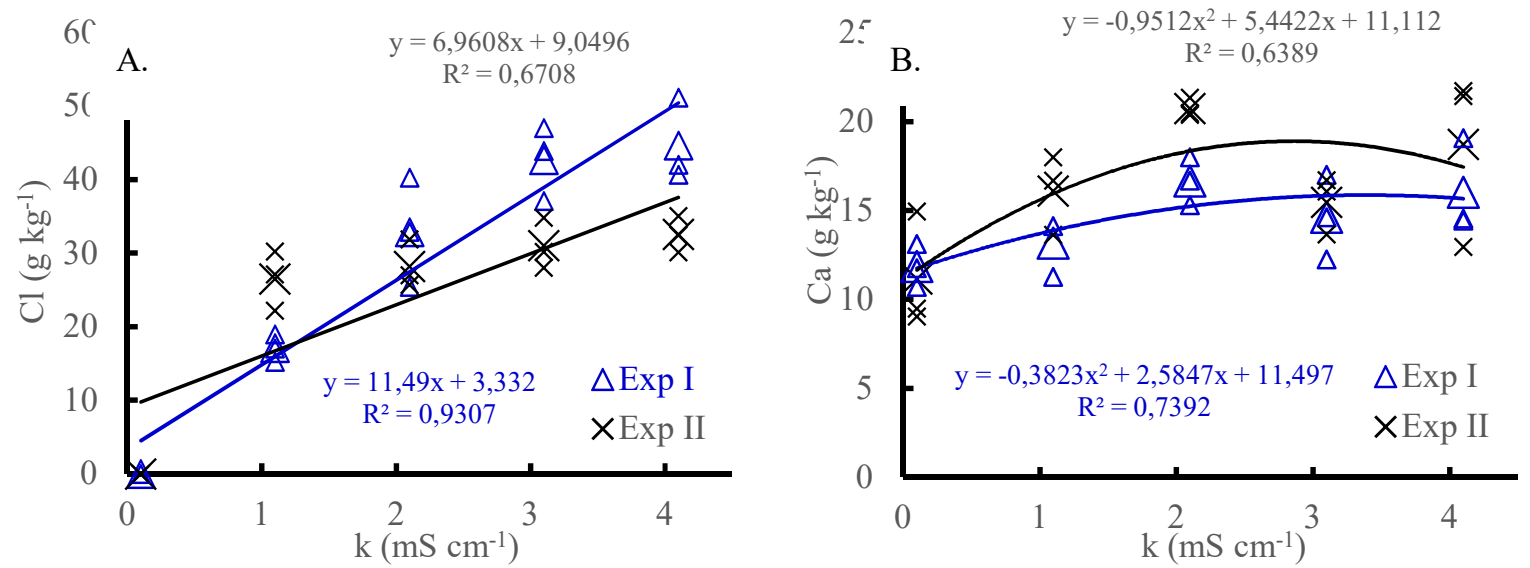

Figura 3: Concentração de cloretos (A) e cálcio (B) nas folhas da alface crespa e americana em função do aumento da condutividade elétrica.

Sobre o cálcio observa-se com o aumento da condutividade elétrica, houve aumento no experimento I até $16,0 \mathrm{~g} \mathrm{~kg}^{-1}$ e no experimento II aumentou com uma leve diminuição nos tratamentos mais salobros até $19,0 \mathrm{~g} \mathrm{~kg}^{-1}$. Paulus et al. (2012) e Soares et al. (2016), ao avaliar os minerais de alface crespa variedade 'Verônica' e variedade 'Tainá', encontraram resultados de 55,0 e 60,0 $\mathrm{g} \mathrm{kg}^{-1}$ de cloreto nos níveis mais salobros de 8,2 e $5,3 \mathrm{mS} \mathrm{cm}^{-1}$ respectivamente.

De acordo com Malavolta (2006), concentrações em excesso de cloretos nas folhas podem causar amarelamento nas folhas, no entanto não foram verificados esse tipo de sintomas nas folhas das alfaces com os níveis de tratamentos estudados neste trabalho. Sobre o cálcio, Paulus et al. (2012) encontraram resultados em média de $10,0 \mathrm{~g} \mathrm{~kg}^{-1}$ e comportamento linear decrescente com o aumento da CEa, esse comportamento não está de acordo com os experimentos I e II ao utilizar o concentrado devido as concentrações de cálcio de $122,5 \mathrm{mg} \mathrm{L}^{-1}$ e no trabalho dos autores a solução era isenta de cálcio, composta apenas de $\mathrm{NaCl}$.

Segundo Malavolta (2006) a concentração ideal de cálcio em folhosas é de $12,5 \mathrm{~g} \mathrm{~kg}^{-1}$, e a deficiência pode provocar clorose nas extremidades das folhas. Apesar das concentrações de cálcio estarem em excesso nos experimentos, o autor não relaciona sintomas para esse fato. Verifica-se na Figura $4 A$ e $4 B$ as concentrações de ferro e magnésio encontradas nos experimentos, nota-se que as concentrações máximas de ferro atingiram 2,78 e 1,68 $\mathrm{g} \mathrm{kg}^{-1}$ nos experimentos I e II no tratamento T4. Enquanto que o magnésio, os resultados não apresentaram diferenças significativas apresentando em média 3,35 e 3,30 $\mathrm{g} \mathrm{kg}^{-1}$ nos experimentos I e II. 
Malavolta (2006) estabelece concentrações ideais para o cultivo de alface entre 0,8 e $1,0 \mathrm{~g} \mathrm{~kg}^{-1}$ o excesso de ferro pode causar manchas necróticas nas folhas, no entanto esse sintoma não foi encontrado no presente estudo. O ferro ainda auxilia nos processos de fotossíntese, respiração e fixação biológica de nitrogênio. Os resultados de magnésio estão de acordo com Paulus et al. (2012) que foi de $2,5 \mathrm{~g} \mathrm{~kg}^{-1}$, no entanto o comportamento foi linear decrescente, chegando a $1,9 \mathrm{~g} \mathrm{~kg}^{-1}$ no tratamento mais salobro. Esse fato se deve as reposições feitas pelos autores que continha água salinizada apenas com $\mathrm{NaCl}$, ao contrário deste trabalho que possuía concentração de magnésio no tratamento T5 de 138,6 $\mathrm{mg} \mathrm{L}^{-1}$ e manteve os níveis de magnésio comprovando a diferença linear decrescente entre o trabalho citado.
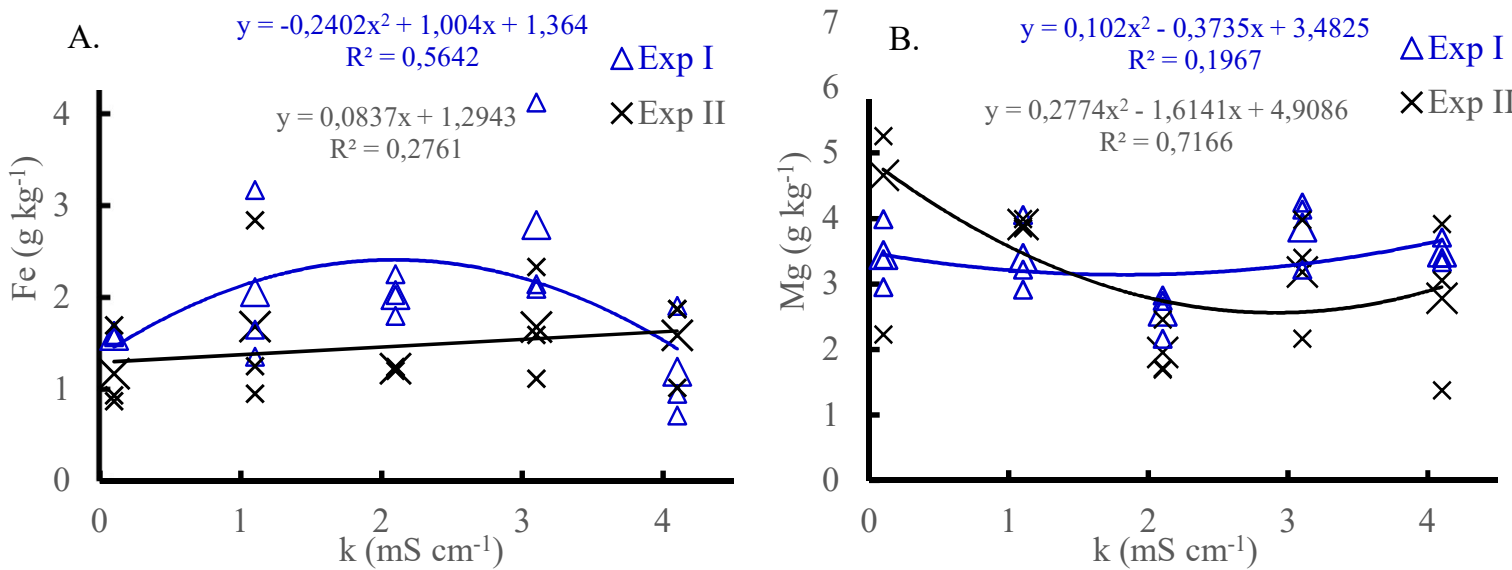

Figura 4: Concentração de ferro (A) e magnésio (B) nas folhas da alface crespa e americana em função do aumento da condutividade elétrica.

Malavolta (2006) afirma que o magnésio possui função estrutural na clorofila e nos processos de fotossíntese e respiração. As concentrações recomendadas em tecido seco são de $3,5 \mathrm{~g} \mathrm{~kg}^{-1}$. A deficiência de magnésio pode causar sintomas visuais como clorose das folhas e o autor não identificou sintomas em caso de excesso.

Percebe-se que de forma geral a alface crespa acumulou mais nutrientes como sódio, cloretos, ferro e magnésio e a alface americana apenas potássio e cálcio, e de acordo com a análise da MFPA na Figura 5 observa-se que a alface crespa apresentou 15,9\% de decréscimo linear por acréscimo unitário de CEa e a alface americana $11,9 \%$, isso implica que, a alface americana apresentou maior tolerância com os níveis de tratamentos estudados.

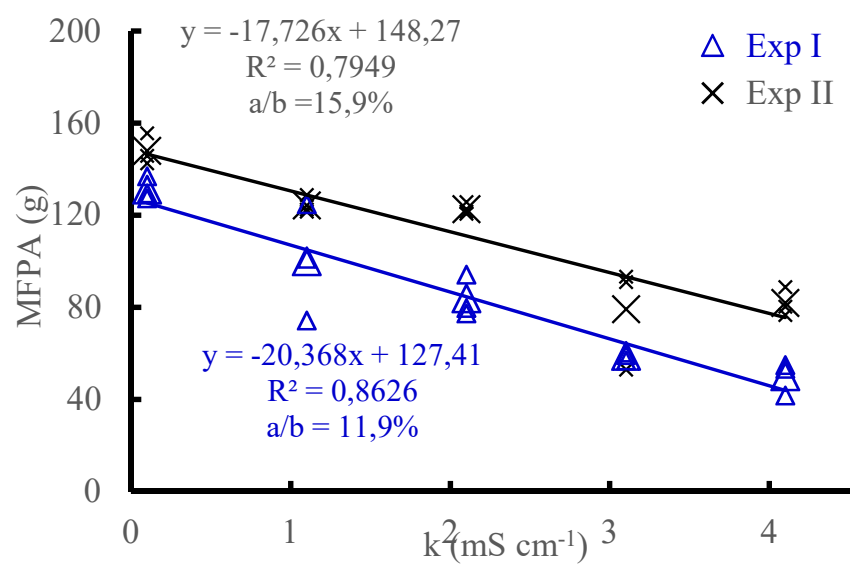

Figura 5: Massa fresca da parte aérea dos experimentos com alface crespa e americana em função do aumento da condutividade elétrica. 
Soares et al. (2015) ao cultivar alface americana variedade 'Tainá' em sistema hidropônico NFT, sobre os níveis de salinidade variando de 0,2 a $5,2 \mathrm{mS} \mathrm{cm}^{-1}$ obtidos a partir da adição de $\mathrm{NaCl}$ observou redução maiores que no presente trabalho de MFPA em 15,22\%. Estudando a produção de alface crespa variedade 'Vera' também variando entre 0,2 e 5,2 $\mathrm{mS} \mathrm{cm}^{-1}$, mas, a partir da diluição de água de poço para preparar os níveis dos tratamentos, Santos et al. (2010) observou reduções de 17,06\% por acréscimo de CEa. Todos esses autores citados utilizaram seus tratamentos tanto no preparo quanto nas reposições diárias de água e também não houve reposição nutrientes, com exceção do tratamento controle.

Soares et al. (2010) combinou água salobra preparada com a adição de $\mathrm{NaCl}$ com CEa variando de 2,1 a $8,6 \mathrm{mS} \mathrm{cm}^{-1}$ para preparar a solução nutritiva e água doce para repor as perdas diárias no cultivo da alface crespa variedade 'Verônica' e constatou reduções lineares de 10,9\%. No presente trabalhos essas reduções foram maiores, pelo fato de não haver combinação de água doce e salobra. Santos et al. (2010) utilizando o concentrado da osmose inversa diluída com água de abastecimento para cultivar alface crespa variedade 'Vera' observou redução de $17,7 \%$ estando de acordo com as reduções encontradas nesse trabalho que variou de $15,9 \%$ e 11,9 , demonstrando que a alface crespa crocante e americana gloriosa foram mais tolerantes do que a estudada pelos autores para o parâmetro MFPA, com os níveis de salinidade de seus tratamentos variando entre 1,4 e $5,5 \mathrm{mS} \mathrm{cm}^{-1}$.

\section{CONCLUSÕES}

Com os níveis dos tratamentos estudados a alface crespa variedade 'crocante' acumulou mais nutrientes do que a alface americana variedade 'gloriosa'. A massa fresca da alface americana apresentou menores decréscimos por incremento de condutividade elétrica. Em regiões com acesso restrito de água doce, o uso do concentrado pode ser utilizado no cultivo hidropônico das alfaces crespa e americana variedades 'crocante e gloriosa' com redução de 15,9\% e 11,9\% respectivamente da massa fresca das plantas.

\section{REFERÊNCIAS}

APHA. American Public Health Association. Standard method for examination of water and wastewater. 21 ed. Washington: APHA, 2005.

ALVES, M. S.; SOARES, T. M.; SILVA, L. T.; FERNANDES, J. P.; OLIVEIRA, M. L. A.; PAZ, V. P. S.. Estratégias de uso de água salobra na produção de alface em hidroponia NFT. Revista brasileira de engenharia agrícola e ambiental, v.15, n.5, 2011. DOI: http://dx.doi.org/10.1590/S141543662011000500009

AOAC. Association Of Official Analytical Chemists. Official methods os analysis of AOAC International. Gaitheersburg, 1997.

BOYSEN, B.; HENTHORNE, L. State-of-art of reverse osmosis desalination pretreatment. Desalination, v.356, n.39, p.129139, 2014. DOI: https://doi.org/10.1016/j.desal.2014.10.039
BRASIL. Resolução CONAMA n³57. Classificação de águas, doces, salobras e salinas do Território Nacional. Brasília: DOU, 2005.

CAVALCANTI, J. E. W. A.. Proposição de novo modelo de operação e manutenção dos dessalinizadores das águas salobras do semiárido brasileiro. São Paulo: Instituto de Engenharia, 2015.

DIAS, N. S.; OLIVEIRA, A. M.; NETO, O. N. S.; BLANCO, F. F.; REBOLÇAS, J. R. L.. Concentração salina e fases de exposição à salinidade do meloeiro cultivado em substrato de fibra de coco. Revista Brasileira de Fruticultura, Jaboticabal, v.33, n.3, p.915-921, 2011.

FURLANI, P. R.. Instruções para o cultivo de hortaliças de folhas pela técnica de hidroponia/NFT. Campinas: Instituto Agronômico, 1998.

GUSMÃO, T. A. S. G.; GUSMÃO, R. P. G.; SOUSA, S.; MATA M. E. R. M. C.; DUARTE, M. E. M.; FIGUEIREDO, R. M. F.; 
MOREIRA, R. T.. Mineral content in French type bread with sodium replacement using fluorescence spectrometry $X$-rays by energy dispersive. African Journal of Biotechnology, v.14, n.51, p.3333-3339, 2015.

IAL. Instituto Adolfo Lutz. Normas Analíticas, métodos químicos e físicos para a análise de alimentos. 4 ed. São Paulo: IAL, 2008.

MALAVOLTA, E.. Avaliação do estado nutricional das plantas: princípios e aplicações. 2 ed. Piracicaba: POTAFOS, 2006.

PAULUS, D.; DOURADO, N. D.; PAULUS, E.. Análise sensorial, teores de nitrato e de nutrientes de alface cultivada em hidroponia sob águas salinas. Horticultura Brasileira, v.30, n.18-25, 2012.

SANCHEZ, A. S.; NOGUEIRA, I. B. R.; KALID, R. A.. Uses of the reject brine from inland desalination for fish farming, spirulina cultivation, and irrigation of forage shrub and crops. Desalination, v.364, n.34, p.96-107, 2015. DOI: https://doi.org/10.1016/j.desal.2015.01.034

SANTOS, A. N.; SOARES, T. M.; SILVA, E. F. F.; SILVA, D. J. R.; MONTENEGRO, A. A.. Cultivo hidropônico de alface com água salobra e rejeito da dessalinização em Ibimirim/PE. Revista Brasileira de Engenharia Agrícola e Ambiental, v.14, n.8, p.961-969, 2010. DOI: http://dx.doi.org/10.1590/S141543662010000900008
SANTOS, E. S.; GAMA, E. M.; FRANÇA, R. S.; SOUZA, A. S.; MATOS, R. P.. Espectrometria de fluorescência de raios-x na determinação de espécies químicas. Enc. Bio. Centro Científico Conhecer, Goiânia, v.9, n.17, 2013.

SANTOS, R. S. S.; DIAS, N. S.; SOUSA NETO, O. N.; GURGEL, M. T.. Uso do rejeito da dessalinização de água salobra no cultivo da alface (Lactuca sativa L.) em sistema hidropônico NFT. Ciênc. agrotec, v.34, n.4, p.983-989, 2010. DOI: http://dx.doi.org/10.1590/S1413-70542010000400026

SARMENTO, J. D. A.; MORAIS, P, L, D.; ALMEIDA, M. L. B.; NETO, O. N. S.; DIAS, N. S.. Qualidade e conservação da alface cultivada com rejeito da dessalinização. Revista Caatinga, Mossoró, v.27, n.3, p.90-97, 2014.

SOARES, H. R.; SILVA, E. F. F.; SILVA, G. F.; LIRA, R. M.; BEZERRA; R. R.. Mineral nutrition of crisphead lettuce grown in a hydroponic system with brackish water. Revista Caatinga, Mossoró, v.29, n.3, p.656-664, 2016.

SOARES, H. R.; SILVA, G. F.; PEDROSA, E. M. R.; ROLIM, M. M.; SANTOS, A. N.. Lettuce growth and water consumption in NFT hydroponic system using Brackish water. Revista Brasileira de Engenharia Agrícola e Ambiental, v.19, n.7, p.636-642, 2015.

SOARES, T. M.; DUARTE, S. N.; SILVA, E. F. F.; JORGE, C. A. Combinação de águas doce e salobra para produção de alface hidropônica. Rev. bras. eng. agríc. ambient., v.14, n.7, 2010.

A CBPC - Companhia Brasileira de Produção Científica (CNPJ: 11.221.422/0001-03) detém os direitos materiais desta publicação. Os direitos referem-se à publicação do trabalho em qualquer parte do mundo, incluindo os direitos às renovaç̃ões, expansões e disseminações da contribuiç̃o, bem como outros direitos subsidiários. Todos os trabalhos publicados eletronicamente poderão posteriormente ser publicados em coletâneas impressas sob coordenação da Sustenere Publishing, da Companhia Brasileira de Produção Científica e seus parceiros autorizados. Os (as) autores (as) preservam os direitos autorais, mas não têm permissão para a publicação da contribuição em outro meio, impresso ou digital, em português ou em tradução. 